\title{
INDIRECT FIELD-ORIENTED CONTROL OF FIVE-PHASE INDUCTION MOTOR DRIVES
}

\author{
Z. M. S. Elbarbary* , and S. A. Mahmoud** \\ "Faculty of Engineering - KFS University \\ ${ }^{* *}$ Faculty of Engineering, Shebin El-Kom - Minoufiya University
}

\begin{abstract}
This paper proposes an indirect field oriented controller for five-phase induction motor drives. The controller is based on indirect vector control technique. Simulation is carried out by using the Matlab/Simulink package. The performance of the proposed system is investigated at different operating conditions. The proposed controller is robust and suitable for high performance fivephase induction motor drives. Simulation results validate the proposed approaches.

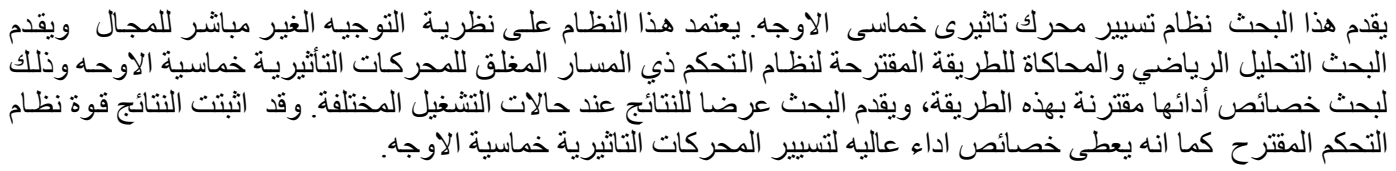

Keywords: Five-phase Induction motor, five-phase Inverter

\section{INTRODUCTION}

Over the years; induction motor (IM) has been utilized as a workhorse in the industry due to its easy build, high robustness, and generally satisfactory efficiency. Multi-phase machines have found wide applications in transport,

textile manufacturing and aerospace since few years. In electrical drive applications, three-phase drives are widely used for their convenience. However, high-phase number drives possess several advantages over conventional three-phase drives such as: reducing the amplitude and increasing the frequency of torque pulsations,

reducing the rotor harmonic currents, reducing the current per phase without increasing the voltage per phase, and lowering the dc-link current harmonics and higher reliability. By increasing the number of phases, it is also possible to increase the torque per rms ampere for the same machine volume [1-5].

Applications involving high power may require multiphase systems, in order to reduce stress on the switching devices. There are two approaches for supplying high power systems; one approach is the use of multilevel inverters supplying three-phase machines and the other approach is multi leg inverters supplying multiphase machines. Much more work has been done on multilevel inverters. It is interesting to note that the similarity in switching schemes between the two approaches: for the multilevel inverter the additional switching devices increase the number of voltage levels, while for the multi leg inverter, the additional number of switching devices increases the number of phases [6].The recent research works on multiphase machines can be categorized into multi-phase pulse width modulation (PWM) techniques for multiphase machines, harmonic injection to produce more torque and to achieve better stability [5], fault tolerant issues of multi-phase motor drives, series/ parallel connected multi-phase machines [6] .

In Ref. [7], an n-phase space vector PWM (SVPWM) scheme can be described in terms of the applying times of available switching vectors on the basis of the space vector concept. However, the paper only focuses on how to realize a sinusoidal phase voltage. Much research on control method and running performance of five-phase drive with twolevel inverter was made. Another research has been done on a multiphase two-level nonsinusoidal SVPWM [9].

The power rating of the converter should meet the required level for the machine and driven load. However, the converter ratings cannot be increased over a certain range due to the limitation of the power rating of semiconductor devices. One solution to this problem is using multi-level inverter, where switches of reduced rating are employed to develop high power level converters. The advent of inverter fed-motor drives also removed the limits of the number of motor phases. This fact made it possible to design machine with more than three phases and brought about the increasing investigation and applications of multi-phase motor drives [10, 14]. 
The five-phase induction motor drives have many more space voltage vectors than the threephase induction motor drives. The increased number of vectors allows the generation of a more elaborate switching vector table, in which the selection of the voltage vectors is made based on the real-time values of the stator flux and torque variations.

In this paper, An indirect rotor field orientedbased speed control of high performance induction motor drive is presented. The effectiveness of the proposed scheme is tested at different operating conditions. Simulation results are presented and discussed.

\section{MATHEMATICAL MODEL OF FIVE - PHASESE INDUCTION MOTOR}

Squirrel-cage five-phase induction motor is represented in its d-q synchronous reference frame. The winding axes of five-stator winding are displaced by 72 degrees. By increasing the number of phases, it is also possible to increase the torque per ampere for the same machine volume. In this analysis the iron saturation is neglected.

The general equations of the five-phase induction motor can be introduced as follows:

The stator quadrature-axis voltage is given by:

$$
V_{q s}=R_{s} i_{q s}+\frac{d \lambda_{q s}}{d t}+\omega \lambda_{d s}
$$

The stator direct-axis voltage is given by:

$$
V_{d s}=R_{s} i_{d s}+\frac{d \lambda_{d s}}{d t}+\omega \lambda_{q s}
$$

For the stationary reference frame $\omega=0$, substitute into Equations (1) and (2) yields:

$$
V_{q s}=R_{s} i_{q s}+\frac{d \lambda_{q s}}{d t}
$$

$$
V_{d s}=R_{s} i_{d s}+\frac{d \lambda_{d s}}{d t}
$$

The stator q-axis flux linkage is given by:

$$
\begin{aligned}
\lambda_{q s} & =L_{s} i_{q s}+L_{m} i_{q r} \\
& =\left(L_{l s}+L_{m}\right) i_{q s}+L_{m} i_{q r} \\
\lambda_{q s} & =L_{l s} i_{q s}+L_{m}\left(i_{q r}+i_{q s}\right)
\end{aligned}
$$

The stator $\mathrm{d}$-axis flux linkage is given by:

$$
\begin{aligned}
\lambda_{d s} & =L_{s} i_{d s}+L_{m} i_{d r} \\
& =\left(L_{l s}+L_{m}\right) i_{d s}+L_{m} i_{d r} \\
\lambda_{d s} & =L_{l s} i_{d s}+L_{m}\left(i_{d r}+i_{d s}\right)
\end{aligned}
$$

The electromagnetic torque is given by:

$$
\begin{gathered}
T_{e}=\frac{5}{2} \frac{p}{2}\left(\lambda_{d s} i_{q s}-\lambda_{q s} i_{d s}\right) \\
T_{e}-T_{l}=j \frac{d \omega}{d t}+B \omega
\end{gathered}
$$

\section{VECTOR CONTROL OF 5-PHASE IM}

The theory of indirect field oriented control is applied for the Five-phase induction motor. The application of the vector control scheme to such arrangement is simple, and can provide fastdecoupled control of torque and flux. In Fig.1, the motor speed, $\omega_{m}$ is compared to a command speed, $\omega^{*}$, and the error signal is processed by the PI controller, to generate the torque-component current command $\mathrm{Iq}^{*}$. The flux-component current command $\mathrm{Id}^{*}$ is calculated according to adopted control strategy. The two current command components are then transformed with the help of rotor position encoder (for angle $\theta \mathrm{e}$ ) to five current commands ia, ib ic ,ie and ie in the stationary reference frame. These current commands are then compared to the actual motor currents by hysteresis current controller to generate the logic pulses for the inverter switches.

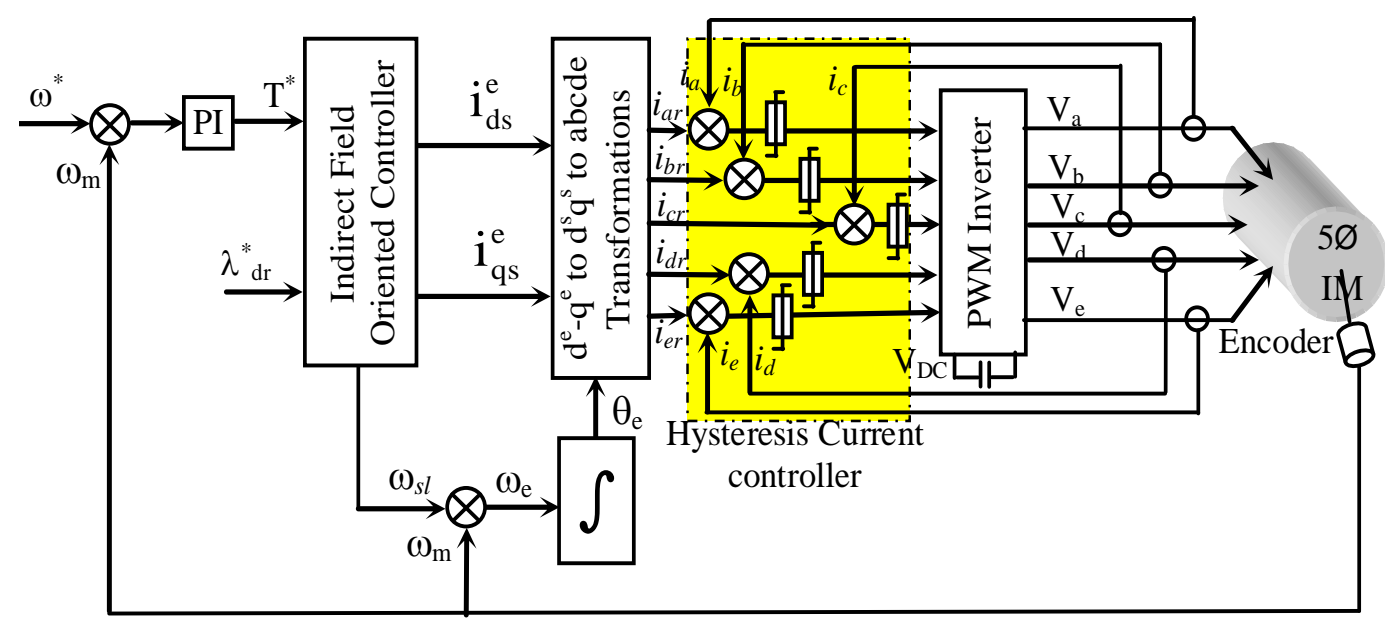

Fig. 1 Block Diagram of the Proposed Speed Control System 
The torque producing current components are calculated from:

$$
\begin{array}{r}
I_{q s}^{*}=\frac{1}{k_{t}} \frac{\left(\omega_{\mathrm{r}}^{*}-\omega_{r}\right)}{\lambda_{d r}^{*}} \frac{K_{p s}\left[1+\tau_{c s} S\right]}{\tau_{c s} S} \\
I_{d s}^{e^{*}}=\frac{1}{L_{m}}\left(1+\tau_{r}^{*} p\right) \lambda_{d r} e^{*}
\end{array}
$$

The angular slip frequency command

$$
\left(\omega_{s l}^{*}\right) \text { is: }
$$

$$
\omega_{s l}^{*}=\frac{L_{m}}{\tau_{r}^{*}} \cdot \frac{I_{q s}^{*}}{\lambda_{d r}^{*}}
$$

Where, ${ }^{\tau} r$ is the rotor time constant and ${ }^{\lambda} d r$ is the direct-axis rotor flux.

The angular frequency is obtained as follows,

$$
\begin{array}{r}
\omega_{e}^{*}=\omega_{s l}^{*}+\omega_{m} \\
\theta_{e}^{*}=\int \omega_{e}^{*} \cdot d t \\
T_{e}=K_{t}\left|\lambda_{d r}^{e}\right| I_{q s}^{e}
\end{array}
$$

Equation (14) is similar to that of the separately excited dc motor and denotes that the torque can initially proportional to the quadrature component of the stator current, ${ }^{* e}{ }^{*}$, if the qe-axis component of the flux becomes zero (de-axis is aligned with the rotor flux axis), and the de-axis component ${ }_{\mathrm{dr}}^{\mathrm{e}}$ is kept constant. This is the philosophy of the vector control technique.

The transformations used for the present system are expressed as follows;

$$
\mathrm{q}^{\mathrm{e}}-\mathrm{d}^{\mathrm{e}} \rightarrow \mathrm{q}^{\mathrm{s}}-\mathrm{d}^{\mathrm{s}}\left\{\begin{array}{l}
\mathrm{i}_{\mathrm{qs}}^{\mathrm{i}^{*}}=\mathrm{i}_{\mathrm{qs}}^{\mathrm{e}^{*}} \cos \theta_{\mathrm{s}}+\mathrm{i}_{\mathrm{ds}}^{\mathrm{e}^{*}} \sin \theta_{\mathrm{s}} \\
\mathrm{i}_{\mathrm{ds}}^{\mathrm{s}^{*}}=-\mathrm{i}_{\mathrm{qs}}^{\mathrm{e}^{*}} \sin \theta_{\mathrm{s}}+\mathrm{i}_{\mathrm{ds}}^{\mathrm{e}^{*}} \cos \theta_{\mathrm{s}}
\end{array}\right\}
$$

where $\theta_{\text {s }}$ represents the sum of the slip and rotor angles.

$$
\mathrm{q}^{\mathrm{s}} \mathrm{d}^{\mathrm{s}} / \mathrm{abced}\left\{\begin{array}{l}
\mathrm{i}_{\mathrm{as}}^{\mathrm{s}^{*}}=\mathrm{i}_{\mathrm{qs}}^{\mathrm{s}^{*}} \cos (\theta)+\mathrm{i}_{\mathrm{ds}}^{\mathrm{s}^{*}} \sin (\theta) \\
\mathrm{i}_{\mathrm{bs}}^{\mathrm{s}^{*}}=\mathrm{i}_{\mathrm{qs}}^{\mathrm{s}^{*}}=\mathrm{i}_{\mathrm{qs}}^{\mathrm{s}^{*}} \cos \left(\theta-\frac{2 \pi}{5}\right)+\mathrm{i}_{\mathrm{ds}}^{\mathrm{s}^{*}} \sin \left(\theta-\frac{2 \pi}{5}\right) \\
\mathrm{i}_{\mathrm{ds}}^{\mathrm{s}^{*}}=\mathrm{i}_{\mathrm{qs}}^{\mathrm{s}^{*}} \cos \left(\theta+\frac{4 \pi}{5}\right)+\mathrm{i}_{\mathrm{ds}}^{\mathrm{s}^{*}} \sin \left(\theta-\frac{4 \pi}{5}\right) \\
\mathrm{i}_{\mathrm{es}}^{\mathrm{s}^{*}}=\mathrm{i}_{\mathrm{qs}}^{\mathrm{s}^{*}} \cos \left(\theta+\frac{2 \pi}{5}\right)+\mathrm{i}_{\mathrm{ds}}^{\mathrm{s}^{*}} \sin \left(\theta+\frac{2 \pi}{5}\right)
\end{array}\right\}
$$

\section{FIVE-PHASE INVERTER}

The modulated phase voltages of five-phase inverter fed five-phase induction motor are introduced as a function of switching logic NA, NB, $\mathrm{NC}, \mathrm{ND}$ and NE of power switches by the following relations:

$$
\left[\begin{array}{l}
V_{a s} \\
V_{b s} \\
V_{c s} \\
V_{d s} \\
V_{e s}
\end{array}\right]=\frac{V_{d c}}{5}\left[\begin{array}{ccccc}
4 & -1 & -1 & -1 & -1 \\
-1 & 4 & -1 & -1 & -1 \\
-1 & -1 & 4 & -1 & -1 \\
-1 & -1 & -1 & 4 & -1 \\
-1 & -1 & -1 & -1 & 4
\end{array}\right]\left[\begin{array}{l}
N A \\
N B \\
N C \\
N E \\
N D
\end{array}\right]
$$

The per-phase switching state having a range of $\mathrm{N}$ $=0$ or 1 .

\section{SIMULATION RESULTS}

The proposed control system shown in Fig. 1 is designed for a simulation investigation. Simulation is carried out using the general purpose simulation package Matlab/Simulink [15], Simulation results are presented to show the effectiveness of the proposed scheme at different operating conditions. These results are classified into two categories; the first represents startup and steady-state while the second represents the dynamic performance.

\subsection{Starting and Steady-State Performance}

The simulation results for start-up and steady-state preformance are illustrated by Figs. 8 to 10. Figure 8.a shows the variation of motor speed from startup to the steady state speed $(150 \mathrm{rad} / \mathrm{sec})$, which is reached after about $200 \mathrm{~m} \mathrm{sec}$. The developed torque and phase current corresponding to same period are shown in Figs. 8.b and 8.c respectively. These current signals are of sine wave profiles on which controller transients are shown.

\subsection{Dynamic Performance}

For studying the dynamic performances of the proposed system, simulation has been carried out. In this respect, the dynamic response of the proposed algorithm is examined by step changes for both speed reference and load torque.

\subsubsection{Speed step change}

To study the dynamic response of the control system due to a step change in the speed command, the motor is subjected to a step increase and decrease in the speed command to evaluate its performance. Figure.9a shows the variation of motor speed, which at $\mathrm{t}=1.0$ second the motor speed command is changed from $100 \mathrm{rad} / \mathrm{sec}$ to $150 \mathrm{rad} / \mathrm{sec}$. and return back again after one second. It can be seen that the motor speed is accelerated and decelerated smoothly to 
follow its reference value with nearly zero steady state error. Figures 9.b and 9.c show the developed torque and phase current corresponding to this step changes respectively. These results ensure the effectiveness of the proposed controller and show good behavior of its dynamic response.

\subsubsection{Load Step Change}

The ability to withstand disturbances in IM control system is another important feature. A step change in the motor load is considered as a typical disturbance. A high performance control system has fast dynamic response in adjusting its control variables so that, the system outputs affected by the load impact will recover to the original status as soon as possible. The dropped aptitude of the system output such as rotor speed and its recovering time are the important performance specifications. Figure 10a shows the speed response when a full load impact is applied for one second. The motor started at no load and the full load, (3 N.m), is applied for one second.The corresponding developed torque is shown in Fig10b. Fig.10c show motor phase current, which increases with loading and decreases with load release.

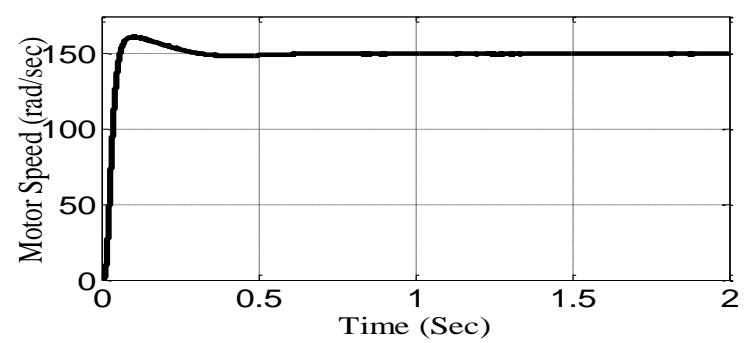

(a)

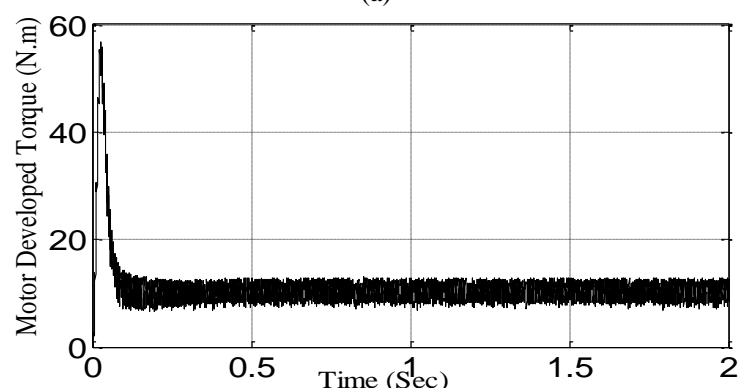

(b)

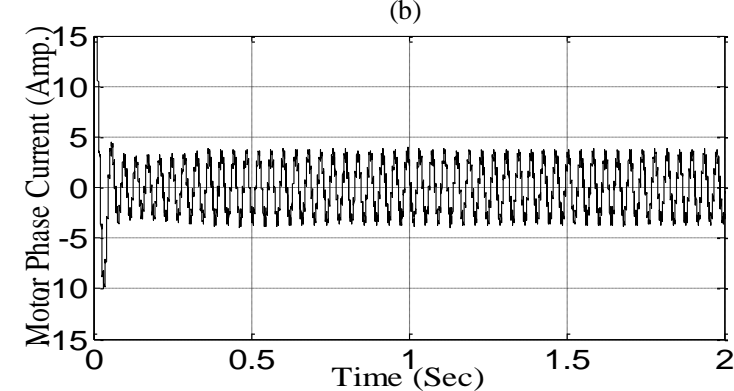

(c)

Fig.8 Startup and steady-stat performance

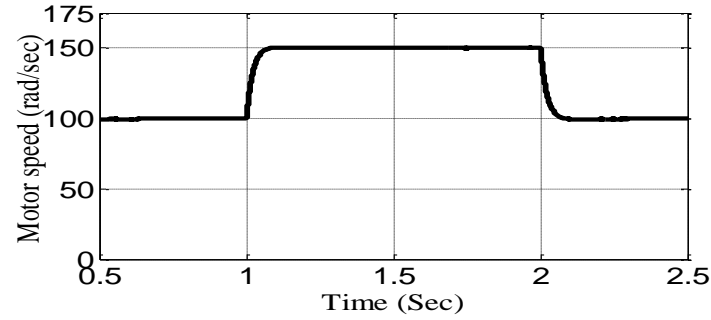

(a)

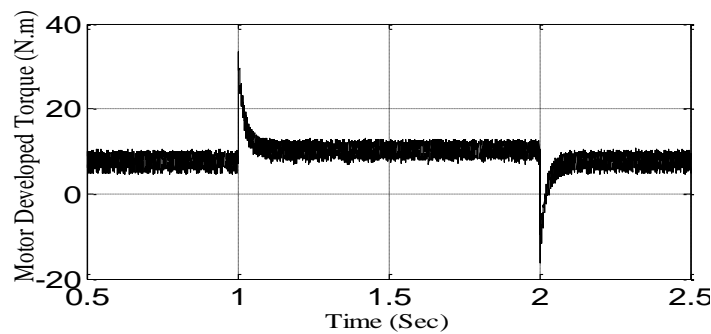

(b)

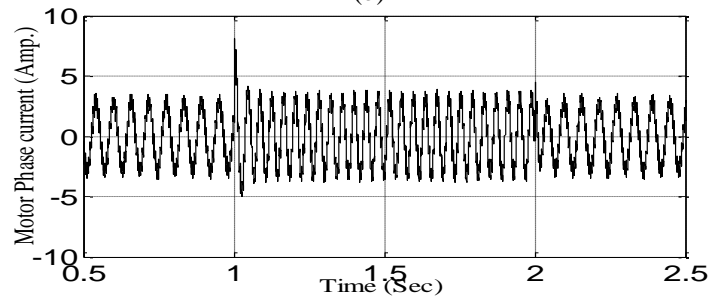

(c)

Fig.9 Speed step change

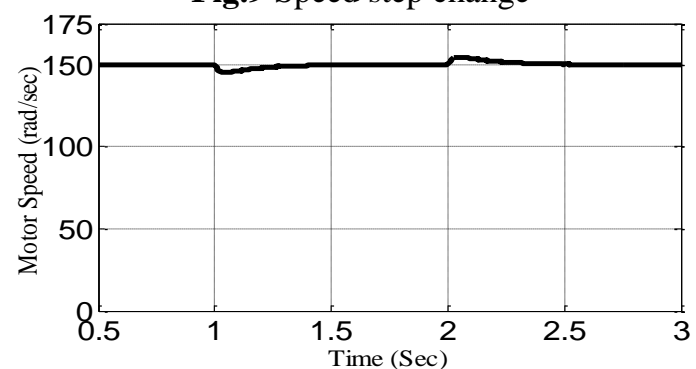

(a)

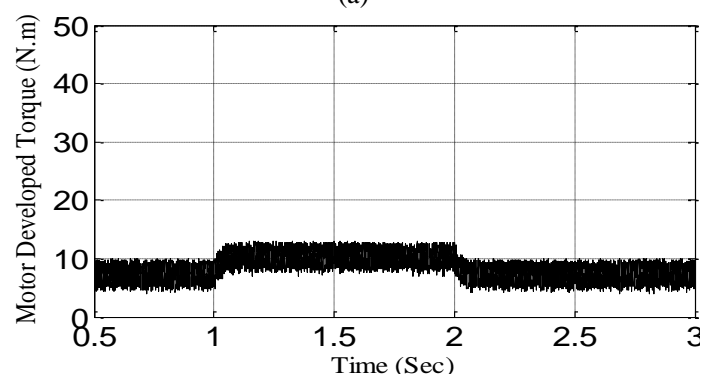

(b)

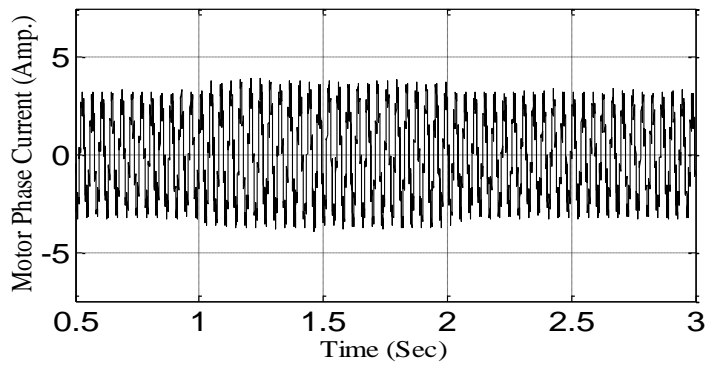

(c)

Fig.10 Load impact 


\section{CONCLUSIONS}

This paper presents a speed control of five-phase induction motor. The control algorithm is based on indirect field oriented control. The effectiveness of the proposed speed control algorithm has been investigated under dynamic and steady-state operation. The results show that the effectiveness and robustness of the proposed speed control method.

\section{REFERENCES}

[1] Levi, E., Bojoi, R., Profumo, F., Toliyat, H.A., and Williamson, S., "Multiphase induction motor drives technology status review"' IEE Elec. Power appl., 2007, (in press).

[2] Singh, G.K., "Multi-phase induction machine drive research - a survey", Electric Power Systems Research, 61, pp. 139-147,2002.

[3] E. E. Ward and H. Härer, "Preliminary investigation of an inverter-fed 5-phase induction motor," Proc. IEE, Vol. 116,No. 6, pp. 980-984, 1969

[4] Williamson, S., and Smith, A.C., "Pulsating torque and losses in multiphase induction machines", IEEE Trans. on Industry Applications, vol. 39, no. 4, pp. 986-993, 2003.

[5] G.D. Holmes, T.A. Lipo, "Pulse Width Modulation for Power Converters - Principles and Practice," IEEE Press Series on Power Engineering, John Wiley and Sons, Piscataway, NJ, USA, 2003.

[6] Toliyat, H.A., Waikar, S.P., and Lipo, T.A., 'Analysis of simulation of five-phase synchronous reluctance machines including third harmonic airgap MMF', IEEE Trans. On Industry Applications, vol. 34, no. 2, pp. 332339, 1998.

[7] Xu, H., Toliyat, H.A., and Petersen, L.J., 'Rotor field oriented control of a five-phase induction motor with the combined fundamental and third harmonic currents', Proc. IEEE Applied Power Electronics Conference APEC, Anaheim, CA, pp. 392-398, 2001.

[8] Xu, H., Toliyat, H.A., and Petersen, L.J., 'Fivephase induction motor drives with DSP-based control system', IEEE Trans. on Power Electronics, vol. 17, no. 2, pp. 524-533,2002.

[9] G.Grandi, G.Serra, A.Tani, "Space vector modulation of a seven-phase voltage source inverter", in Proc. Int. Symp. On Power Electronics, Electrical Drives, Automation and Motion SPEEDAM, Taormina, Italy, 2006, pp. S8-6-S8-13.
[10] J.W. Kelly, E.G. Strangas, J.M. Miller, "Multiphase space vector pulse width modulation," IEEE Trans. on Energy Conversion, vol. 18, no. 2, 2003, pp. 259-264.

[11] G.Grandi, G.Serra, A.Tani, "General analysis of multi-phase systems based on space vector approach", in Proc. EPEPEMC Conf., Portoroz, Slovenia, 2006, pp. 834-840.

[12] Durán, M.J., Levi, E. "Multi-dimensional approach to multiphase space vector modulation" in Proceedings IEEE 32nd Annual Conference of the IEEE Industrial Electronics Society. IECON, Paris, France, 2006.

[13] Toliyat, H.A., Shi, R., Xu, H., “A DSP-based vector control of five-phase synchronous reluctance motor", Proc. IEEE IAS Annual Meeting, Rome, Italy, 2000, CD-ROM paper No.40_05.

[14] Toliyat, H.A., Xu, H., "DSP-based direct torque control (DTC) for five-phase induction machines" Proc. Int. Power electronics Conf. IPEC, Tokyo, Japan, 2000, p. 1195-1200.

[15] Matlab/Simulink Toolbox User's Guide, The Math works Inc., Natick, MA, USA, May 1998.

\section{Nomenclature}

Rs : stator phase resistance (ohm)

$\mathrm{I}_{\mathrm{qs}}$ : stator quadrature axis current $(\mathrm{A})$

$\mathrm{I}_{\mathrm{ds}}$ : stator direct axis current (A)

$\mathrm{I}_{\mathrm{qr}}$ : rotor quadrature axis current (A)

$\mathrm{I}_{\mathrm{dr}}$ : rotor direct axis current (A)

$\mathrm{L}_{\mathrm{s}}$ : stator equivalent inductance $(\mathrm{H})$

$\mathrm{L}_{\mathrm{ls}}$ : stator leakage inductance $(\mathrm{H})$

$\mathrm{L}_{\mathrm{m}}$ : magnetizing inductance $(\mathrm{H})$

$\mathrm{T}_{1}$ : load torque (N.m)

$\mathrm{J}$ : inertia of motor $\left(\mathrm{Kg} \cdot \mathrm{m}^{2}\right)$

B : friction coefficient (N.m.s/rad)

\section{Appendix}

\begin{tabular}{ll} 
Motor Parameter & \\
\hline No. of poles & 4 \\
Stator resistance & $7.4826 \mathrm{ohm}$ \\
Rotor resistance & $3.6840 \mathrm{ohm}$ \\
Rotor leakage inductance & $0.0221 \mathrm{H}$ \\
Stator leakage inductance & $0.0221 \mathrm{H}$ \\
Mutual inductance & $0.4114 \mathrm{H}$ \\
Supply frequency & $50 \mathrm{~Hz}$ \\
Motor speed & $1500 \mathrm{r} . \mathrm{p} . \mathrm{m}$. \\
Supply voltage & $380 \mathrm{volts}$ \\
Inertia & $0.02 \mathrm{~kg} . \mathrm{m}^{2}$ \\
\hline
\end{tabular}

